\title{
Slit lamps and lenses: a potential source of nosocomial infections?
}

\author{
Bianka Sobolewska ${ }^{1} \cdot$ Michael Buhl $\mathbb{1}^{2} \cdot$ Jan Liese $^{2} \cdot$ Focke Ziemssen (1)
}

Received: 25 January 2017 / Revised: 8 August 2017 / Accepted: 30 November 2017 / Published online: 30 January 2018

(c) The Royal College of Ophthalmologists 2018

\begin{abstract}
Purpose The aim of the study was to evaluate the bacterial contamination level of contact surfaces on slit lamps and the grip areas of lenses.

Methods Within unannounced audits, two regions of the slit lamps (headrest and joystick), indirect ophthalmoscopy devices, and ultrasound probes were obtained with rayon-tipped swab. Non-contact lenses used for indirect fundoscopy were pressed on RODAC (Replicate Organism Detection and Counting) plates. One hundred and eighty-one surfaces were sampled. The total number of colony-forming units was assessed and bacterial species were identified. Spa-typing and antimicrobial susceptibility testing were performed from Staphylococcus aureus isolates.

Results Among the total bacterial isolates from ophthalmological equipment (lenses: 51 of 78 , slit lamps: 43 of 88, ophthalmoscopy helmets: 3 of 8, ultrasound probes: 2 of 7), coagulase-negative staphylococci (CNS) was most frequently found, followed by Micrococcus spp. (lenses vs. slit lamps: $P<0.001$ and $P=0.01$, respectively). The bacterial contamination of lenses $(76 \%)$ was significantly higher than that of slit lamps $(54 \%)(P<0.003)$. A significantly higher contamination with CNS was observed on lenses from residents vs. from consultants $(78 \%$ vs. $35 \%, P=0.01)$. A total of seven different spa-types of $S$. aureus were isolated. No correlation was found between $S$. aureus contamination of different ophthalmological equipments (Spearman's rank correlation coefficient, $\rho=0.04, P=0.75$ ). Methicillin-resistant $S$. aureus was not detected.

Conclusion Bacterial species of the normal skin flora were isolated from the ophthalmological equipment. The bacterial contamination of the portable devices was significantly higher than that of slit lamps. Therefore, proper hygiene of the mobile instruments should be monitored in order to prevent transmission of bacteria in residents and consultants.
\end{abstract}

\section{Introduction}

Health-care-associated infections (HAIs) or nosocomial infections are not present at the time of first contact or admission and include infections appearing after discharge, which were acquired by patients in hospital or other healthcare facilities (World Health Organization). They are a common cause of mortality and morbidity as well as one of the most common adverse events in health care. In addition, HAIs lead to high financial costs. According to the Center for Disease Prevention and Control in the United States and

Bianka Sobolewska

bianka.sob@gmx.de

1 Center for Ophthalmology, Eberhard-Karls University, Tuebingen, Germany

2 Institute of Medical Mircrobiology and Hygiene, Eberhard-Karls University, Tuebingen, Germany
Europe, 4.5 and $6 \%$ of patients are infected with at least one HAI during a hospital stay [1]. In a multistate pointprevalence survey of HAIs, $5.6 \%$ of patients had eye, ear, nose, throat, or mouth infection [2]. The most common nosocomial infections in eye hospitals are acute conjunctivitis, followed by upper respiratory tract infections and endophthalmitis. [3]. In patients with postoperative endophthalmitis, the most frequently isolated bacteria were coagulase-negative staphylococci (CNS), including Staphylococcus epidermidis [3, 4]. Further, ocular infections caused by methicillin-resistant Staphylococcus aureus (MRSA) appear to be increasing in incidence, prevalence, and also resistance to other antibiotics, especially fluoroquinolones and erythromycin [5-12].

Potential reservoirs of HAIs are different surfaces including stethoscopes [13, 14], bed rails [15], faucet handles [16], and ophthalmic equipments, such as slit lamps [17], operating microscopes [18], tonometer tips [19-22], and felt-tipped marker pens [23]. In the digitial medicine also mobile phones [24] and computer keyboards [16] 
become more relevant vehicles for the transmission of pathogenic microorganisms. Other potential vectors for nosocomial infections are inappropriately or unsuccessfully decontaminated surgical instruments [25] or reusable laserprotective eyeware [26], and reuse of contaminated eye drops [27, 28]. Besides, microbial hand contamination during an eye examination contributes to the risk of transmission not only due to contact with the patient's skin but also due to direct contact with the patient's eye discharge and tears [29]. Further, ophthalmologists with conjunctivitis may spread infections, too [30].

However, the small and often personalized equipment of ophthalmologists must not be forgotten as potential vehicles for transmission of bacteria. Previous studies did not include the handheld lenses [17-19, 29], although frequent disinfection of this equipment between patients in accordance to standardized hygiene guidelines appears very unlikely. The endeavors to improve the discipline of hand hygiene would be irrelevant if the contact areas would be ignored [29].

Due to the rise of multi-drug resistance, bacterial contamination has to be taken seriously, just as the risk of adenoviral keratoconjunctivitis. [31]. Therefore, the aim of this study was to evaluate the bacterial contamination level of the whole spectrum of the ophthalmological equipment: lenses, slit lamps, indirect ophthalmology helmets, and handheld ultrasound probes.

\section{Materials and methods}

\section{Setting}

The study was conducted at a tertiary center and teaching hospital (Center for Ophthalmology, Eberhard-Karl University, Tuebingen, Germany). The hospital offers accommodation with 76 beds (7000 inpatient treatments per year and 94,300 outpatient cases per year). This work adhered to the tenets of the Declaration of Helsinki, and the Institutional Ethics Committee of the University of Tuebingen granted approval with a waiver of informed consent for this study. The samples were pseudonymized and de-identified prior to analysis. According to the disinfection recommendations, all devices used in this study should be cleaned with non-woven wipes distributed with didecyldimethyl ammonium chloride and quaternary ammonium compounds, benzyl-C12-16-alkyldimethyl, chlorides.

\section{Sample collection}

Samples were taken from the slit lamps, non-contact lenses used for indirect fundoscopy, indirect ophthalmology helmets, and ultrasound probes within an unannounced audit by one qualified person (between 11 a.m. and 1 p.m.). We examined all diagnostic (non-contact) lenses used for indirect fundoscopy, which were found in the workplace. Most physicians carried 90 D (and similar) and 20 D lenses with them $(n=20)$. Different variants and commercial versions providing slight differences of magnification or visual field (Superfield $\mathrm{NC}^{\circledR}$, SuperPupil ${ }^{\circledR}$, Super Vitreofundus ${ }^{\circledR}$, Digital Wide-Field ${ }^{\circledR}$, Digital High Mag ${ }^{\circledR}, 66$ D, 78 D) were analyzed within this subgroup. Only a small group of personal contact lenses (Goldmann three-mirror contact lens, Super Quad ${ }^{\circledR}, n=3$ ) was tested. Two surfaces of the slit lamps, headrests and joysticks, were chosen for microbiological examination due to direct contact with the skin of the patients and with the ophthalmologists' hands, respectively (interim wipe disinfection not applied). Due to the use of chin papers, this part of the slit lamps was not examined. Two surfaces of the slit lamps, the headrest and the joystick, as well as the indirect ophthalmoloscopy helmets and ultrasound probes were obtained using rayon-tipped swabs (plastic stick rayon-tipped Venturi Transystem ${ }^{\mathrm{TM}}$ Amies with charcoal sterilized by ionizing radiation, BD, made by COPAN, Italy). Sampling of the lenses was conducted by gently pressing on RODAC (Replicate Organism Detection and Counting) plates $\left(24 \mathrm{~cm}^{2}\right)$ for $5 \mathrm{~s}$ [32].

\section{Culture}

All specimens were delivered to the laboratory immediately after collection. RODAC plates with inhibitors against disinfecting agents (Oxoid) and Columbia sheep blood (Oxoid) plates were incubated aerobically at $37^{\circ} \mathrm{C}$ for $48 \mathrm{~h}$. The total number of colony-forming units (CFU) was assessed and bacterial species were examined following a standardized operational procedure. This included preliminary identification using catalase test and DiaMondiaL Staph Plus Kit, followed by MALDI-TOF-MS (Axima Assurance, Shimadzu) where appropriate. Staphylococcus aureus isolates were further characterized as for their spatypes (Staphylococcus protein A) and using the Ridom SpaServer (Ridom).

\section{Statistical analysis}

Data are presented as median and ranges. The bacterial contamination of lenses and slit lamps was compared using Wilcoxon's signed-rank tests for continuous variables and with $\chi^{2}$ analysis for categorical variables. Correlation between the bacterial contamination of different ophthalmological equipments was measured by Spearman's correlation coefficient. A $P$ value $<0.05$ was defined as statistically significant. All statistical analyses were performed using commercial software (SPSS version 22.0, SPSS Inc.). 
A

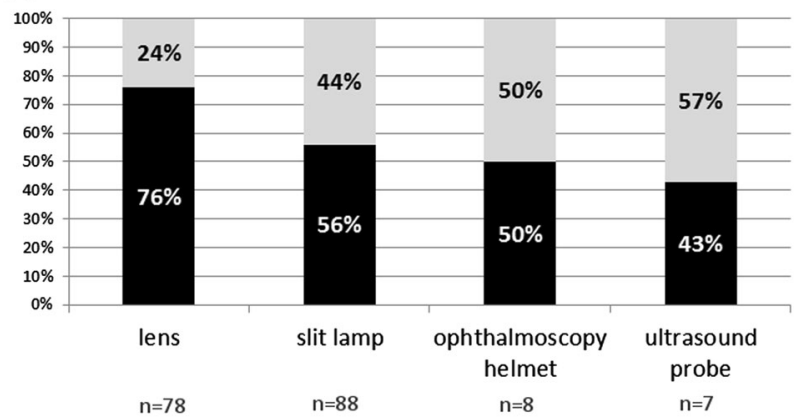

B

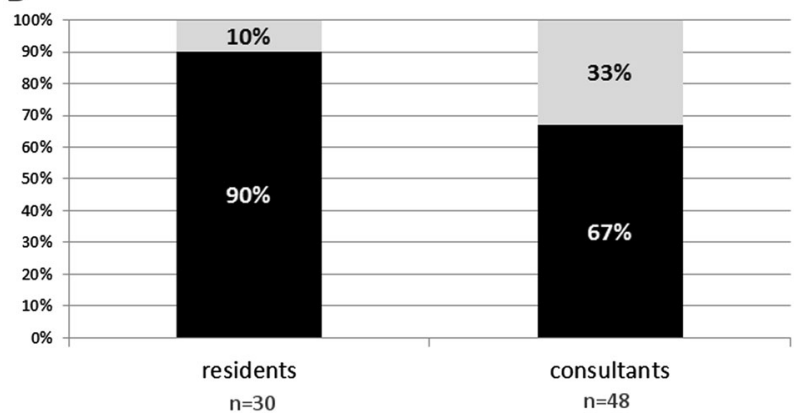

Fig. 1 a A total of bacterial contamination of lenses $(n=78)$, slit lamps $(n=88)$, ophthalmoscopy helmets $(n=8)$, and handheld ultrasound probes $(n=7)$; b A total of bacterial contamination of lenses in residents $(n=30)$ and consultants $(n=48)$ (black-percentage of samples with bacterial contamination, gray-percentage of samples without bacterial contamination)

\section{Results}

Seventy-eight samples from lenses (30 from residents and 48 from consultants), 88 samples from slit lamps, 8 samples from indirect ophthalmology helmets, and 7 samples from ultrasound probes. The slit lamps were in 40 different rooms and lenses came from 39 doctors (18 residents and 21 consultants). A total of 181 samples were analyzed for the presence of microorganisms.

Out of the total samples, bacteria were isolated from 59 (76\%) of 78 lenses and $56(54 \%)$ of 103 devices other than lenses (slit lamps: 49 of 88 , ophthalmoscopy helmets: 4 of 8, handheld ultrasound probes: 3 of 7) (Fig. 1a).

Among the total bacterial isolates from lenses, CNS 51 (86\%) were followed by Micrococcus spp. 20 (34\%), other aerobic bacteria $10(17 \%)$, and $S$. aureus 7 (12\%). In addition, two (3\%) non-fermenting bacteria and molds were found (Fig. 2).

In the slit lamp samples together with indirect ophthalmology helmets and ultrasound samples, CNS 48 (86\%) were followed by Micrococcus spp. 13 (23\%), other aerobic bacteria $6(11 \%), S$. aureus $4(7 \%)$, and molds $2(4 \%)$ (Fig. 2).
The maximum contamination of lenses was $71 \mathrm{CFU}$, followed by slit lamps (3 CFU), indirect ophthalmology helmets (2 CFU), and ultrasound probes (1 CFU) (Table 1).

The bacterial contamination of lenses was significantly higher as compared to the bacterial contamination of slit lamps $(P=0.003)$. CNS (lenses vs. slit lamps: median 2 (0-71) CFU/24 $\mathrm{cm}^{2}$ vs. median $0(0-3) \mathrm{CFU} / 24 \mathrm{~cm}^{2}, P<$ $0.001)$ and Micrococcus spp. (lenses vs. slit lamps: median 0 (0-36) CFU/24 $\mathrm{cm}^{2}$ vs. median $0(0-1) \mathrm{CFU} / 24 \mathrm{~cm}^{2}, P=$ $0.015)$ were the most frequently isolated bacteria from the grip areas of lenses (Table 1). No correlation was found between contamination with $\mathrm{CNS}(\rho=0.13, P=0.27)$, Micrococcus spp. $(\rho=0.06, P=0.59)$, and $S$. aureus $(\rho=$ $0.04, P=0.75$ ) of slit lamps and lenses.

A significant difference in contamination with CNS was observed on lenses from residents vs. from consultants (78\% vs. $35 \%, P=0.01$ ). A statistical trend toward significance was observed in total of bacterial contamination between lenses from residents and consultants $(P=0.058)$ (Fig. 1b, Table 2).

A total of seven different spa-types of $S$. aureus were isolated. Two types (t1827 and t2387) were found in different slit lamps and lenses. Staphylococcus aureus t1827 was isolated from two lenses, which belonged to the same doctor, and S. aureus t2387 was isolated from one lens of another doctor and from two different slit lamps.

MRSA was not detected in this study.

\section{Discussion}

This study evaluated, within unannounced audits, 181 samples from lenses, 2 regions of slit lamps (headrest and joystick), sections of indirect ophthalmoscopy devices, and ultrasound probes in order to estimate the contamination rate and spectrum of the microorganisms on these surfaces. The major findings of this study are: (1) CNS were the most frequently isolated microorganisms in all evaluated ophthalmological equipment; (2) the bacterial contamination of lenses was significantly higher in comparison to the slit lamps; (3) the bacterial contamination of lenses from residents showed a statistical trend toward significance in comparison to the lenses from consultants; (4) a significant contamination with CNS was observed in lenses from residents vs. lenses from consultants.

The vast majority of all bacterial species found in this study were part of the resident skin flora. The skin seems to be the most common determinant of ophthalmological equipment contamination. CNS were the most common microorganisms isolated from the slit lamps, including indirect ophthalmology helmets and ultrasounds probes, and lenses which is in accordance with studies on mobile phones [24]. The second most common bacteria isolated 


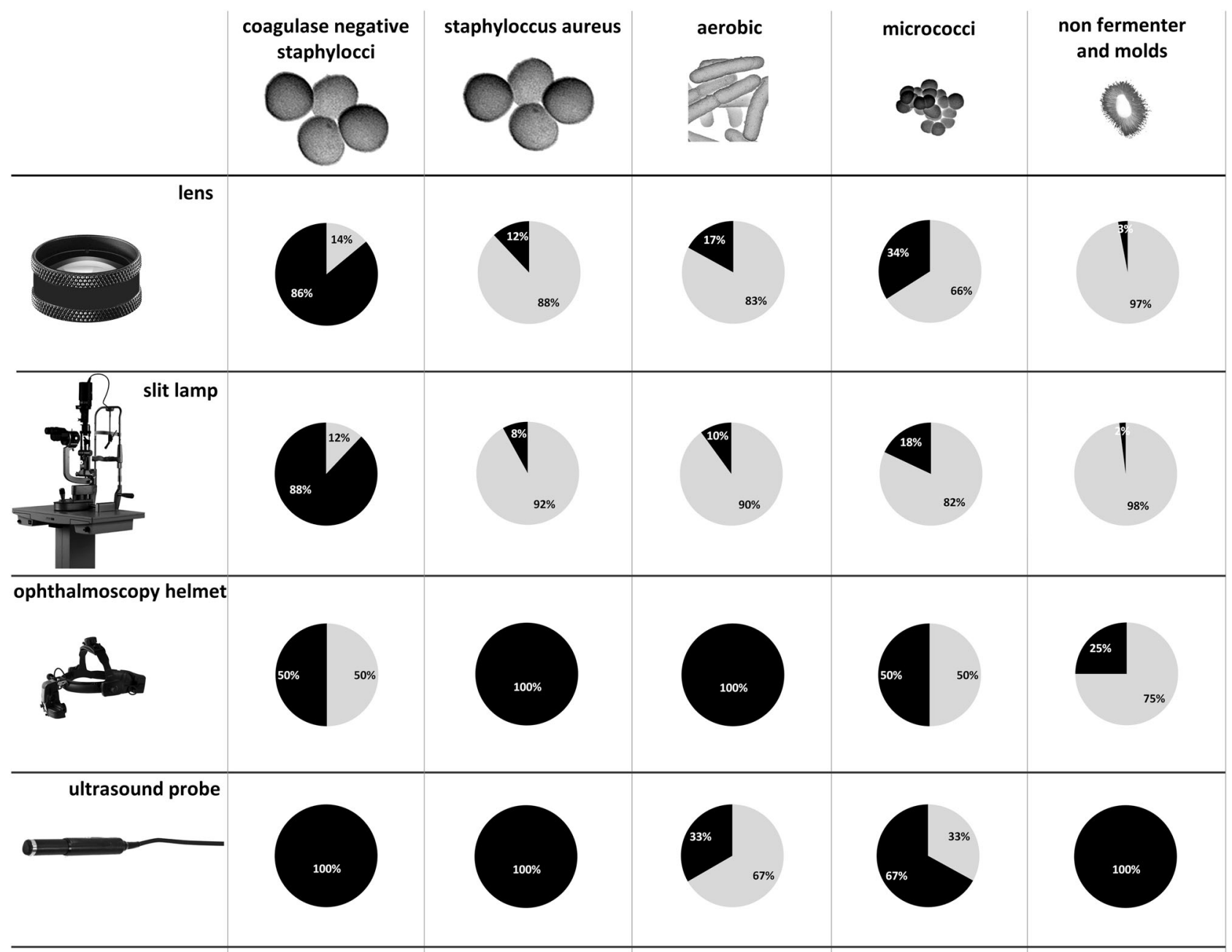

Fig. 2 Spectrum of bacteria implicated in contamination of lenses, slit lamps, ophthalmoscopy helmets, and ultrasound probes (black-percentage of samples with bacterial contamination, gray-percentage of samples without bacterial contamination)

from the ophthalmological equipment were Micrococcus spp., which is also present on normal skin [33] and in the inanimate environment, and does only rarely lead to infections in immunocompromised patients [34]. The third most common isolated bacteria were aerobic bacteria, which are predominant inhabitants of the skin, and are involved in different infections [29]. Staphylococcus aureus was least often found in our study, and no MRSA were cultured. However, the presence of $S$. aureus spa-types t1827 on two lenses from the same doctor and $\mathrm{t} 2387$ on a lens and two different slit lamps suggests that hands may be a source of bacterial cross-contamination. However, no relation was found between $S$. aureus contamination of different ophthalmological equipments.

In our study, the bacterial contamination of lenses was significantly higher in comparison to the slit lamps. Furthermore, the significant contamination levels with CNS were observed in lenses compared to the slit lamps, and also in lenses from residents vs. lenses from consultants. This observation suggests a better hygienic practice of slit lamps than lenses. It has to be pointed out that no lens cleaning instructions existed, and the lenses are not routinely cleaned, in particular not subsequent to every examination. However, considering the results of our study and the fact that lenses are very frequently used, in virtually every eye examination, the optimal method of disinfection should be determined. In addition, considerable variation in the lens contamination, ranging from 0 to $71 \mathrm{CFUs,}$, was observed in this study. These differences in the bacterial contamination level may be associated with the frequency of lens use and disinfection and also the storage of the devices between the eye examinations. A wide discrepancy in the frequency of bacterial contamination was also reported in studies on stethoscope contamination [14].

In addition, a significant contamination level with CNS was observed in the sample from 18 residents (number of lenses: 30) in comparison to lenses from 21 consultants (number of lenses: 48). The results seem to be unrelated to 
Table 1 Spectrum of bacteria implicated in contamination of lenses, slit lamps, ophthalmoscopy helmets, and ultrasound probes

\begin{tabular}{lllll}
\hline $\begin{array}{l}\text { Bacterial } \\
\text { contamination }\end{array}$ & Lenses & $\begin{array}{l}\text { Slit } \\
\text { lamps }\end{array}$ & $\begin{array}{l}\text { Ophthalmoscopy } \\
\text { helmets }\end{array}$ & $\begin{array}{l}\text { Ultrasound } \\
\text { probes }\end{array}$ \\
\hline CNSA: median & 2 & 0 & 0 & 0 \\
CNSA: mean & 5 & 1 & 1 & 0 \\
CNSA: range & $0-71$ & $0-3$ & $0-2$ & $0-1$ \\
SA: median & 0 & 0 & 0 & 0 \\
SA: mean & 0 & 0 & 0 & 0 \\
SA: range & $0-7$ & $0-3$ & 0 & 0 \\
Micr.: median & 0 & 0 & 0 & 0 \\
Micr.: mean & 1 & 0 & 0 & 0 \\
Micr.: range & $0-36$ & $0-1$ & $0-1$ & 0 \\
Aerob.: median & 0 & 0 & 0 & 0 \\
Aerob.: mean & 0 & 0 & 0 & 0 \\
Aerob.: range & $0-3$ & $0-1$ & $0-1$ & $0-1$ \\
\hline Aerob. aerobic & bacta & $C N S A$ & coagulase-native Staphylococ
\end{tabular}

Aerob. aerobic bacteria, CNSA coagulase-negative Staphylococcus aureus, Micr. Micrococcus, SA Staphylococcus aureus

Table 2 Spectrum of bacteria implicated in contamination of lenses in residents and consultants

\begin{tabular}{lll}
\hline Bacterial contamination & $\begin{array}{l}\text { Lenses from } \\
\text { residents }\end{array}$ & $\begin{array}{l}\text { Lenses from } \\
\text { consultants }\end{array}$ \\
\hline CNSA: median & 4 & 1 \\
CNSA: mean & 9 & 3 \\
CNSA: range & $0-71$ & $0-26$ \\
SA: median & 0 & 0 \\
SA: mean & 0 & 0 \\
SA: range & $0-7$ & $0-6$ \\
Micr.: median & 0 & 0 \\
Micr.: mean & 0 & 0 \\
Micr.: range & $0-3$ & $0-1$ \\
Aerob.: median & 1 & 0 \\
Aerob.: mean & 0 & 2 \\
Aerob.: range & $0-9$ & $0-36$
\end{tabular}

Aerob. aerobic bacteria, CNSA coagulase-negative Staphylococcus aureus, Micr. Micrococcus, SA Staphylococcus aureus

the number of doctors or to the number of patients seen in the offices. The residents usually examine a smaller number of patients per day than consultants.

Furthermore, every resident and consultant have their own lenses. As the lenses sometimes lie around next to each other, it occurs that lenses were shared; however, all physicians preferably use their own private lens. Neither residents nor consultants have been reminded or instructed to routinely clean their lenses in the path. Nevertheless, all physicians undertake regular training to improve hygiene education to prevent nosocomial infections, for example, training in hand hygiene. In addition, screening tests are performed to detect carriage of problem germs in physicians as part of the hygiene monitoring program.

Several limitations of this study have to be considered. First, the study was not multicenter. However, the number of samples was not small. Second, we did not investigate the bacterial contamination of physicians' hands [29, 35]. Third, the lenses often have soft linings, which are impossible to clean.

The risk factors for transmission of pathogens to patients are rare hand disinfection and sharing lenses with colleagues, which are an implication of lack of hygiene awareness and wrong personal behavior like "scratching your hair or nose with your finger" [36]. Thus, it is not only sufficient to wear short-sleeved shirts and ban ties but also to remain aware of others routes of cross-contamination [37].

In conclusion, bacterial species of the normal skin flora were isolated from the ophthalmological equipment and the bacterial contamination of the lenses was significantly higher than that of slit lamps. Furthermore, the grip areas of lenses from residents were significantly contaminated with CNS compared to lenses from consultants, although all residents own and use their own lenses and usually examine a smaller number of patients than consultants. Therefore, better hygiene education and determination of cleaning method for lenses could reduce a risk of spreading potential nosocomial pathogens.

\section{Summary}

\section{What was known before}

- Potential reservoirs of HAIs are different surfaces including stethoscopes, bed rails, medical charts, faucet handles, and ophthalmic equipments, such as slit lamps, operating microscopes, tonometer tips, and felt-tipped marker pens.

- In the digitial medicine also mobile phones and computer keyboards become more relevant vehicles for the transmission of pathogenic microorganisms.

- Other potential vectors for nosocomial infections are inappropriately or unsuccessfully decontaminated surgical instruments or reusable laser-protective eyeware, and reuse of contaminated eye drops.

\section{What this study adds}

- Previous studies did not include the handheld lenses.

- The bacterial contamination of lenses (76\%) was significantly higher than that of slit lamps $(54 \%)(P<$ 0.003).

- A significantly higher contamination with CNS was observed on lenses from residents vs. from consultants (78\% vs. $35 \%, P=0.01$ ). 
- Better hygiene education and determination of cleaning method for lenses could reduce a risk of spreading potential nosocomial pathogens.

Acknowledgements We would like to thank the technicians of the hygiene laboratory including Sebastian Grashorn for their excellent technical assistance.

Funding None of the authors has a financial or property interest in any materials or methods mentioned in this manuscript. BS has received one travel grant from Galderma and Novartis. FZ has received speakers' fees or consultancy honoraria from Alcon, Alimera, Allergan, Bayer Healthcare, Pfizer, and Novartis. JL has received speakers' fees from BioMérieux

Author contributions All authors (BS, MB, JL, and FZ) contributed to all of the following: (1) conception and design of the work, acquisition of data, or analysis and interpretation of data, (2) drafting the article or revising it critically for important intellectual content, (3) final approval of the version to be published, and (4) agreement to be accountable for all aspects of the work.

\section{Compliance with ethical standards}

Conflict of interest The authors declare that they have no competing interests.

\section{References}

1. Klevens RM, Edwards JR, Richards CL Jr, Horan TC, Gaynes RP, Pollock DA, et al. Estimating health care-associated infections and deaths in U.S. hospitals, 2002. Public Health Rep. 2007;122:160-6.

2. Magill SS, Edwards JR, Bamberg W, Beldavs ZG, Dumyati G, Kainer MA, et al., Emerging Infections Program HealthcareAssociated Infections and Antimicrobial Use Prevalence Survey Team Multistate point-prevalence survey of health care-associated infections. N Engl J Med. 2014;370:1198-208.

3. Wang Z, Hu S, Jiang Y, Dong N, Lin X, Yu A. Nosocomial infection in an eye hospital: incidence and occurrence patterns. Clin Exp Ophthalmol. 2006;34:650-3.

4. Wu PC, Kuo HK, Li M, Lai IC, Fang PC, Lin SA, et al. Nosocomial postoperative endophthalmitis: a 14-year review. Graefes Arch Clin Exp Ophthalmol. 2006;244:920-9.

5. Shanmuganathan VA, Armstrong M, Buller A, Tullo AB. External ocular infections due to methicillin-resistant Staphylococcus aureus (MRSA). Eye (Lond). 2005;19:284-91.

6. Blomquist PH. Methicillin-resistant Staphylococcus aureus infections of the eye and orbit (an American Ophthalmological Society thesis). Trans Am Ophthalmol Soc. 2006;104:322-45.

7. Freidlin J, Acharya N, Lietman TM, Cevallos V, Whitcher JP, Margolis TP. Spectrum of eye disease caused by methicillinresistant Staphylococcus aureus. Am J Ophthalmol. 2007;144:313-5.

8. Asbell PA, Sahm DF, Shaw M, Draghi DC, Brown NP. Increasing prevalence of methicillin resistance in serious ocular infections caused by Staphylococcus aureus in the United States: 2000 to 2005. J Cataract Refract Surg. 2008;34:814-8.

9. Rathod D, Luqmani N, Webber SK, Hosein IK. Survey of methicillin-resistant Staphylococcus aureus policies in UK eye departments. J Hosp Infect. 2009;72:314-8.
10. Hsiao CH, Chuang CC, Tan HY, Ma DH, Lin KK, Chang CJ, et al. Methicillin-resistant Staphylococcus aureus ocular infection: a 10-year hospital-based study. Ophthalmology. 2012;119:522-7.

11. Amato M, Pershing S, Walvick M, Tanaka S. Trends in ophthalmic manifestations of methicillin-resistant Staphylococcus aureus (MRSA) in a northern California pediatric population. J AAPOS. 2013;17:243-7.

12. Lalitha P, Manoharan G, Karpagam R, Prajna NV, Srinivasan M, Mascarenhas J, et al. Trends in antibiotic resistance in bacterial keratitis isolates from South India. $\mathrm{Br} \mathrm{J}$ Ophthalmol. 2016;101:108-13. E-pub ahead of print.

13. O'Flaherty N, Fenelon L. The stethoscope and healthcareassociated infection: a snake in the grass or innocent bystander? J Hosp Infect. 2015;91:1-7.

14. Longtin Y, Schneider A, Tschopp C, Renzi G, Gayet-Ageron A, Schrenzel J, et al. Contamination of stethoscopes and physicians' hands after a physical examination. Mayo Clin Proc. 2014;89:291-9.

15. Ali S, Moore G, Wilson AP. Effect of surface coating and finish upon the cleanability of bed rails and the spread of Staphylococcus aureus. J Hosp Infect. 2012;80:192-8.

16. Bures S, Fishbain JT, Uyehara CF, Parker JM, Berg BW. Computer keyboards and faucet handles as reservoirs of nosocomial pathogens in the intensive care unit. Am J Infect Control. 2000;28:465-71.

17. Chong YY, Kosmin A, Barampouti F, Kodati S. Bacterial flora on slit lamps. Ann Ophthalmol (Skokie). 2008;40:137-40.

18. Wiggins MN, Uwaydat SH. Microbial contamination of ophthalmic operating microscopes. Eye (Lond). 2007;21:1012-3.

19. Aizman A, Stein JD, Stenson SM. A survey of patterns of physician hygiene in ophthalmology clinic patient encounters. Eye Contact Lens. 2003;29:221-2.

20. Briesen S, Schulze Schwering M, Roberts H, Kollmann M, Stachs $\mathrm{O}$, Behrend $\mathrm{D}$, et al. Minimal cross-infection risk through Icare rebound tonometer probes: a useful tool for IOP-screenings in developing countries. Eye (Lond). 2010;24:1279-83.

21. Hillier RJ, Kumar N. Tonometer disinfection practice in the United Kingdom: a national survey. Eye (Lond). 2008;22:1029-33.

22. Maino AP, Uddin HJ, Tullo AB. A comparison of clinical performance between disposable and Goldmann tonometers. Eye (Lond). 2006;20:574-8.

23. Sim FC, Angadi D, Jarvis GE, Porteous M. Assessing clarity and erasability of commercially available pens for surgical site marking: a comparative study in human volunteers. Patient Saf Surg. 2016;10:11.

24. Ulger F, Dilek A, Esen S, Sunbul M, Leblebicioglu H. Are healthcare workers' mobile phones a potential source of nosocomial infections? Review of the literature. J Infect Dev Ctries. 2015;9:1046-53.

25. Southworth PM. Infections and exposures: reported incidents associated with unsuccessful decontamination of reusable surgical instruments. J Hosp Infect. 2014;88:127-31.

26. Lange VR. Eyewear contamination levels in the operating room: infection risk. Am J Infect Control. 2014;42:446-7.

27. Yap YC, Smith M, Byles D. The reuse of ophthalmic minims: an unacceptable cross-infection risk? Eye (Lond). 2010;24:1421-2.

28. Somner JE, Cavanagh DJ, Wong KK, Whitelaw M, Thomson T, Mansfield D. The precautionary principle: what is the risk of reusing disposable drops in routine ophthalmology consultations and what are the costs of reducing this risk to zero? Eye (Lond). 2010;24:361-3.

29. Lam RF, Hui M, Leung DY, Chow VC, Lam BN, Leung GM, et al. Extent and predictors of microbial hand contamination in a tertiary care ophthalmic outpatient practice. Invest Ophthalmol Vis Sci. 2005;46:3578-83. 
30. Webber SK, Blair DG, Elkington AR, Canning CR. Ophthalmologists with conjunctivitis: are they fit to work? Eye (Lond). 1999;13:650-2.

31. Dart JK, El-Amir AN, Maddison T, Desai P, Verma S, Hughes A, et al. Identification and control of nosocomial adenovirus keratoconjunctivitis in an ophthalmic department. $\mathrm{Br} \mathrm{J}$ Ophthalmol. 2009;93:18-20.

32. Smith KJ, Neafie R, Yeager J, Skelton HG. Micrococcus folliculitis in HIV-1 disease. Br J Dermatol. 1999;141:558-61.

33. Chen KH, Chen LR, Wang YK. Contamination of medical charts: an important source of potential infection in hospitals. PLoS ONE. 2014;9:e78512.
34. Kloos WE, Musselwhite MS. Distribution and persistence of Staphylococcus and Micrococcus species and other aerobic bacteria on human skin. Appl Microbiol. 1975;30:381-5.

35. Hesje CK, Sanfilippo CM, Haas W, Morris TW. Molecular epidemiology of methicillin-resistant and methicillin-susceptible Staphylococcus aureus isolated from the eye. Curr Eye Res. 2011;36:94-102.

36. Dancer SJ. Put your ties back on: scruffy doctors damage our reputation and indicate a decline in hygiene. BMJ. 2013;346: f3211.

37. Weber RL, Khan PD, Fader RC, Weber RA. Prospective study on the effect of shirt sleeves and ties on the transmission of bacteria to patients. J Hosp Infect. 2012;80:252-4. 